\title{
Selection of Plastic Waste Recycling Material Suppliers By Means of Analytic Hierarchy Process
}

\author{
Syaifuddin Yana ${ }^{1}$, Badaruddin $^{1}$, Syamsul Rizal $^{2}$ and Taufik Hidayat ${ }^{3}$ \\ \{syaifuddin.yana@serambimekkah.ac.id\} \\ ${ }^{1}$ Engineering and Economics Faculty, Universitas Serambi Mekkah, Aceh, Indonesia. \\ ${ }^{2}$ Economics Faculty, Universitas Muhammadyah, Aceh, Indonesia. \\ ${ }^{3}$ Bank Syariah Mandiri Meulaboh Branch, Aceh Barat, Indonesia
}

\begin{abstract}
The aim of this research is to determine how to manage the capability level for compliance of plastic waste as part of a raw material for the manufacture of plastic chips by the supplier by using a analytical hierarchy process (AHP). The research clarify the process from purchasing the raw materials, production, storage until selling the plastic chips to the end buyer. The research will prescribe the sequence of supplier performance in terms of providing raw material by using a hierarchical analysis process. The analysis outcome of the process hierarchy matrix obtained that the order of supplier which can meet the requests of the manufacturer is a supplier 1, 3, 2 and 4, in which the first dealer/supplier has the highest value. The sequence is the most reflective reflection for the satisfaction and compliance of production needs required by the manufacturer in this moment. Criteria for the assessment on a transaction of this plastic waste are: the type of plastic waste, price, colour, quality and quantity. The research is performed in one district in the province of Aceh, Indonesia. Wider scale should be conducted in the future. This research can help the manufacturer the better decision that they can manage in the future to run the manufacturer business of plastic waste conversion. This paper contributes to help the plastic waste business such as manufacturer, suppliers, others related to this activity.
\end{abstract}

Keywords: Analysis Hierarchy Process Matrix, Suppliers, Industrial Processing Waste Plastics and Plastic Chips.

\section{INTRODUCTION}

The process of establishing supply chain and management has a very important role as the business transformation of conventional systems to new systems. Many studies have performed a review of the supply chain with different levels of success and, more importantly, it positively impacts on the implementation of supply chain (SC) activities to the company in overall activity. SC and logistics activities can help develop strategies to minimize risks, help fix SC problems, and can avoid complex and inefficient problems that can certainly impact the biggest losses for the company. 
To support the processing of plastic products required many sources of plastic waste that actually exist in the community and surroundings. Nevertheless, industry of the plastic waste processing into plastic chips are common and many in Aceh. Along with this, garbage collection activities, especially plastic waste, are something we often see in our environment and also in garbage collection and garbage dumps.

The chain process of collecting the plastic waste is tiered from scavengers either using collectors sack or basket at the back or scavengers simple pedicabs every day to accumulate the plastic waste and subsequently sold to the collectors who in this activity is regarded to as the collecting agent. The collectors are also divided ranging from small-scale of collectors, medium, up to large scale or in a chain of activities is also a small collector is further selling plastic waste collected to the large agency or sold to other manufacturers for processing into chips.

Furthermore, after the chips, plastic products produced by local manufacturer are then sold to other larger manufacturers and of course a large manufacturer of plastic chips will then process it into finished plastics products that have higher sales value. All activities are initiated from the collection, storage, sale and subsequent processing and distribution all together is a chain of important events that have sustained economic value. Of course, these activities from the supplier to the consumer until ending of industrial chain of activities which are integrated into a networking activity, namely the SC, or better known as SC management.

\section{LITERATURE REVIEW}

\subsection{Supply Chain Management}

Set of connections of facilities and activities that concerned with conveying a manufactured goods from raw materials all the approach through the customer is called as a SC. When it involves planning and organizing substance, parts and finished product distribution from the suppliers to the consumers it is known as SC management [1]. SC management requires effective knowledge management to attain competitive advantage and it also represents the sustainability perspective in the decision-making process [2]. In 1970s Thomas L. Saaty has developed a decision method which is known today as AHP. AHP assists organization to find one of the best suits their objective and perceptive of the problem. Thus, definitely provides a wide-ranging and reasonable agenda for structuring a decision problem, for replecting and quantifying its elements, for concerning those elements to overall goals, and for evaluating alternative solutions [3]. Korpela et al. [4] using the AHP for the allocation of production capacity, while Aghezzaf [5] uses relaxation Langrangian for the plant site selection and planning capacity, also Jung et al. [6] used a simulation technique and many varieties of methods used to overcome the problems in SC management.

SC management is more persistent on the integration and organization of the stream of commodities and services and the flow of information through the SC to create it more reactive to consumer needs while reducing the total cost by Russell and Taylor [7]. According to Li Ling [8], the SC is sequence of activities and decisions are interconnection inter each other to integrate suppliers, manufacturing, warehouse, transportation services, retailers and consumers more efficiently. It can be concluded that the goods and services can be distributed in the amount, timing and precise location to minimize costs in order to fulfill the requirements of the end consumer. 
One of the keys to success and an important thing to be considered by the company is the distribution activities because the activity will directly affect the distribution cost of the SC and consumer needs. The proper distribution network be able to used to achieve various objectives of the SC, ranging from low cost to high response against customers requested [9].

In the business sector, it is seen the impact of an increase in a competitive market environment and the kind of adaptive strategy needed to succeed in a dynamic business environment to make continuous changes. Success in a competition will be determined by the level of success in building and maintaining cooperation and alliances [10]. SC management will greatly depend on coordination between enterprise and business interactions related products, services, financial resources and information. The objective of the SC management is to coordinate relations between actors in the $\mathrm{SC}$, which creating an organized manner in the $\mathrm{SC}$ to interact with one another. The scope of the SC will depend on the consensus of the actors involved in building relationships in the SC system.

The SC must develop the ability to adapt to different and changes environmental in order to face the increasing competitive business environment and high uncertainty in the market. The required design is an adaptive $\mathrm{SC}$ and it is capable to respond to the market environment which is easy to change.

Moreover, there are several resemblance and distinction between SC management and logistics management. The equation of the two, namely: (1) Concerning both organizing of the stream of commodities or services, (2) Both are concerned about purchase, movement, storage, transportation, administration, and allocation of commodities and (3) Both involve efforts to rectify the efficiency and effectiveness of the management of goods.

\subsection{Analytical Hierarchy Process}

Saaty [11], the basis of the AHP is a concept that restricted to the scope of the environmental problem, which using a mathematical approach as the basis of this concept and also use a structured by using a consistent matrix approach and associated with eigenvector's and generate the corresponding weights [11][12].

The application of AHP has been lengthily used in making decisions to solve various problems, which this approach by using multiple criteria in a system consisting of various levels [13]. This mode has the capability to resolve the various problems with complex structure, multi-person, multi-attribute, and the problem of multi-period hierarchical [14]. In addition, the AHP is very useful in making decisions that complicated and complex where at times the goal to be taken were conflicting and differently to get a consensus decision [15]. AHP method can help in make a decision to resolve the various problems such as supplier selection, in which case they are to pick the greatest combination of suppliers [16].

Omkarprasad and Kumar [17], the AHP approach are the method that provides the criteria ranked according to the needs of buyers who also leads to more informed decisions on supplier selection. Some of the main advantages of utilizing the AHP technique are where buyers get a good overview of the performance of suppliers using criteria hierarchy and evaluating suppliers.

According to Yahya and Kingsman [18], The AHP method was introduced by Saaty used for decision-making to decide priorities in choosing a supplier. AHP application can be widely used in making a variety of decisions, in which involve multivel criteria in a system of various levels. From AHP feature, then generates a numerical priority of subjective knowledge expressed in the pairwise proportion matrix estimates. This method is also used and is very useful in evaluating the weight of suppliers in the field of marketing activities or in providing 
its ranking. Nevertheless, it is still considered to be not easy to decide the weight and the corresponding sequence of each alternative.

In the AHP application, also requires the use of data based on the experience, knowledge and subjective judgment on a decision by the decision maker. There are some disadvantages of using this method that does not judge the risks and uncertainty of the ability of suppliers [14].

AHP is a measurement theory to handle the quantitative as well as insubstantial criteria that have been utilized to various fields of science, for instance decision theoritics and clash decision [19]. AHP is a solving the problem structure and have a systematic procedure to represent the elements of each issue, [11]. AHP is created based on three main principles, namely: decomposition, comparative assessment and creation of priorities. In AHP begins by describing a complex, multi-criteria problem into a chain of command in which each one of stage consists of elements that are managed by some of the decomposed into group of elements [20]. Afterwards, using a measurement methodology for arranging the priorities among the elements in all phase of the hierarchy. The final step in using AHP is to create the priority elements to build the overall priority to get an alternative decision. AHP is different from the conventional decision analysis methodology which does not require decision-makers to be able to guess the numerical development as a subjective judgment is easily included in the process and assessment can be done in verbal mode [21].

\subsection{Logistic Performance and the Criteria for Supplier Selection}

Initially the management of SC management and logistics operations are defined similarly, as both focus on the effective performance of the activities related to the optimization of the distribution and manufacturing and accelerate the flow of inventory and information through a channel system [22]. Therefore, a lot of writers who have used the words of SC management and logistics as a synonym. For instance, Thomas and Griffin define SCM as materials management and information flow in the form of facilities, such as vendors, assembly plants, manufacturing and distribution centers [23].

Rapid changes occur in almost all markets, where suppliers have to be flexible to restructure their logistics networks in a very short period of time. Therefore, business process reengineering (BPR) has received its site among essential approaches when improving or reorganization issues such as SC. According to a survey of the permanent needs of the European Logistics Association for re-engineering the logistics process has been received by European logistics leaders and other manufacturers who will follow future trends, (G. Roux, 1997).

Fawcett et. al., [24] depiction of the achievement of the logistics company's size is about the key factors are cost, quality, delivery, flexibility and innovation. This is not an easy decision to make because there are many different criteria for a good partner. Criteria to develop partnerships with the SC organization members is usually driven by expectations of quality, cost efficiency, dependency shipping, volume flexibility, and customer service information [25]-[28]. In different types of companies, there are different special requirements in terms of vendor evaluation. For instance, in the Europe automotive industry, logistics, supplier performance measurement functions include information management, the approach of clarification and formulation, supplier motivation, communication, alignment and coordination, assessment making as well as priorities, and learning [29]. 


\section{METHODS}

The methods and problem-solving approach in which the stages of research to be conducted in this study are as follows:

1. The SC activity that begins with the collection of plastic waste, collected by agents and distributors (collectors) and then sold to producers for processing and then sold to end buyers is another major producer (plastic conversion industry) to be make into diverse types of plastic end products. So part of this activity is a collection from begin to finale processing and sales, including in this transportation service deliver logistics to the destination.

2. Plastic waste suppliers are plastic waste collectors, both small and large scale collectors are somewhile related to as plastic waste collection agencies. Sometimes scavengers can collect waste in relatively small quantities and there is agreement between producers and suppliers (including scavengers).

3. The raw materials in this research is plastic waste that consists of various types, colors, quality and price which will then be used as plastic waste processing materials.

4. The product referred to in this research is plastic chips produced from the processing (production) by using a grinding machine.

5. There are many types of plastics waste are sold by the supplier, but the type that interest the buyers in the market is the type of PP cup and PP injection (polypropylene), PET bottles (Polyethylene Terephthalate) and HDPE (High Density Polyethylene), and others. All raw materials (waste plastic) are made from plastic waste of various kinds of products and consists of a various kind of colors.

6. AHP is used as model approach. With a decision matrix that is used as a tool for decision making on suppliers (distributors) raw material of plastic waste that the best one which will be helping manufacturers to make decision in purchasing.

7. SC intended in this research is described how the process of information that occurred beginning with the purchase of raw materials, production, storage and sales of plastic chips to the end buyer. For a better explanation, the SC will be described the flow of the SC data information.

\section{Discussion and Analysis}

\subsection{SC Mapping (Raw Material Waste Plastic into Chips Plastic)}

The production references in this research needs to be traced the flow of SC system behavior in processing plastic waste processing industry into plastic chips (at producers). It is needed to know first the flow of data and material (feedstock) in clearly and detail. Therefore, it is needed to do the mapping of data and information flow of raw material in several levels. The first level clarify the stream of data and materials in the system in general and the second level defines a more comprehensive flow, and so forth until the flow is completed detailed or can not be specified again. 
a. Information flow and Plastic Waste Data. General

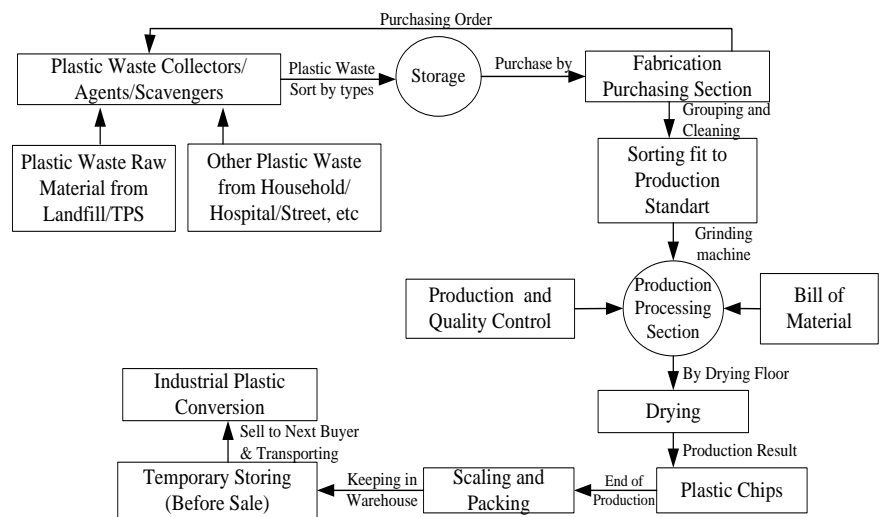

Fig. 1 Presented at The 1st Almuslim International Conference On Science, Technology, and Society (AICOSTS).

b. Data Information Flow and Plastic Waste Purchase.

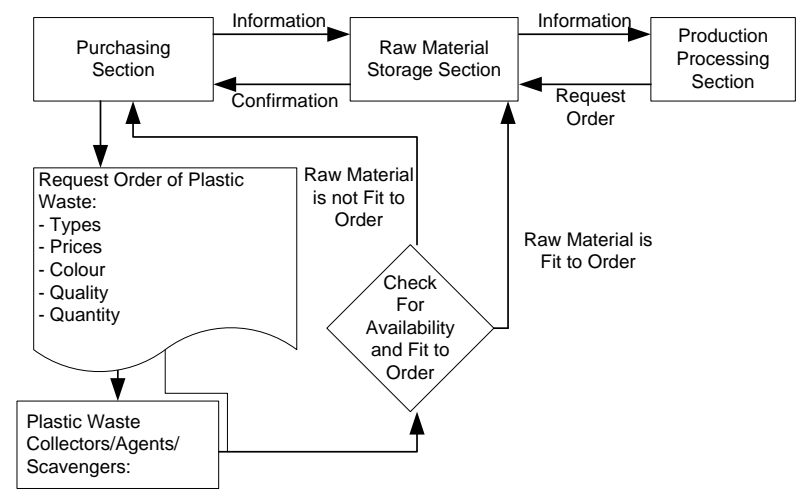

Fig. 2 Figure 2. Presented at The 1st AICOSTS.

c. Information Flow of Plastic Waste.

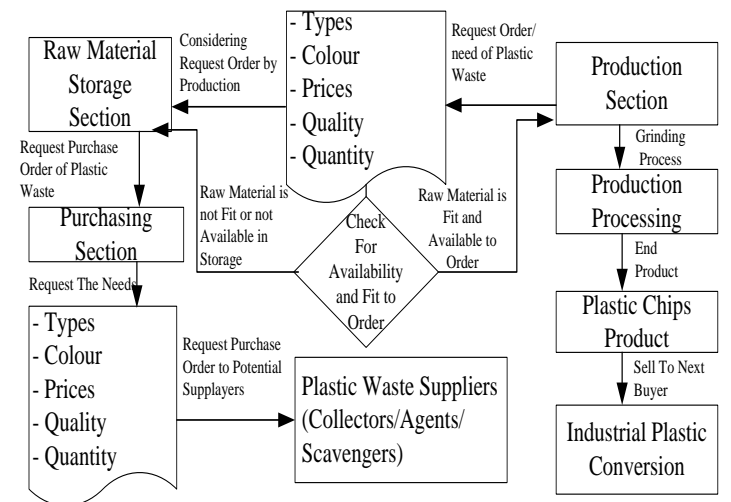

Fig. 3 Presented at The 1st AICOSTS. 
d. Data Information Flow and Plastic Waste Purchase Raw Material (inventories).

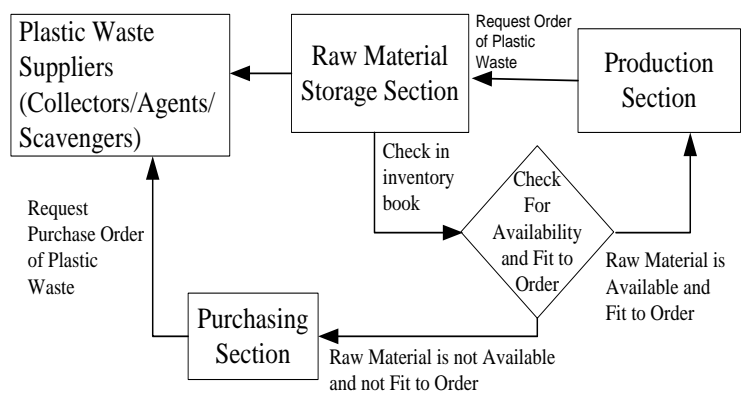

Fig. 4 Presented at The 1st AICOSTS.

e. Information Flow and Plastic Chips Inventories.

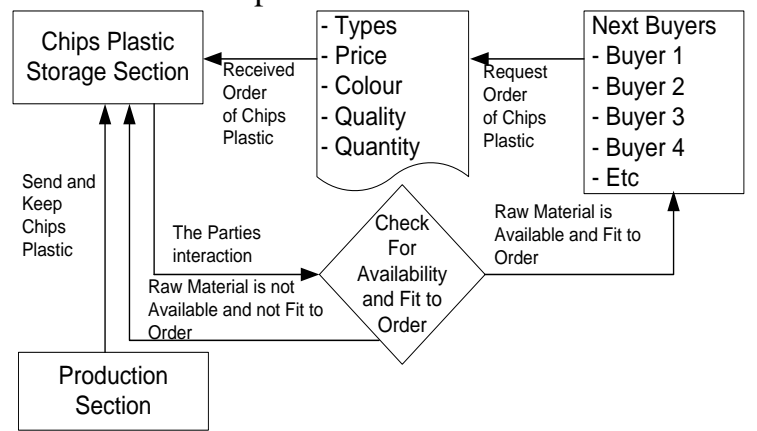

Fig. 5 Presented at The 1st AICOSTS.

\subsection{Plastic Waste Suppliers}

The supplier of plastic waste in the waste business and the processing industry consists of collecting agents (distributors). Once the plastic waste is sorted and cleaned, plastic waste will be collected in a sackcloth to take home before the sale. In general, collection agency activity does not own a formal business entity except the plastic waste processing industry has business entities such as UD, cooperatives or other government agencies. Consequently, in order to assist the assessment, then to group these suppliers will be coded with (S1, S2, S3 and $\mathrm{S} 4)$, the coding is shortened in such a way in order to create it easier to make an assessment.

\subsection{Plastic Waste Suppliers Assessment}

Assessment criteria in SC activities are a reflection of SC activity. The criteria are plastic waste type, price, colour, quality, quantity, and delivery time. Usually industrial / manufacturing considerations in purchases and transactions vary from one manufacturer to another.

\subsection{Plastic Waste Suppliers Assessment}

AHP is a model that will be used in data processing, where the assessment will be given the criteria and sub criteria weight. The AHP model is appropriate to apply to cases that are relatively difficult to make and complex decisions using multiple assessment criteria. 


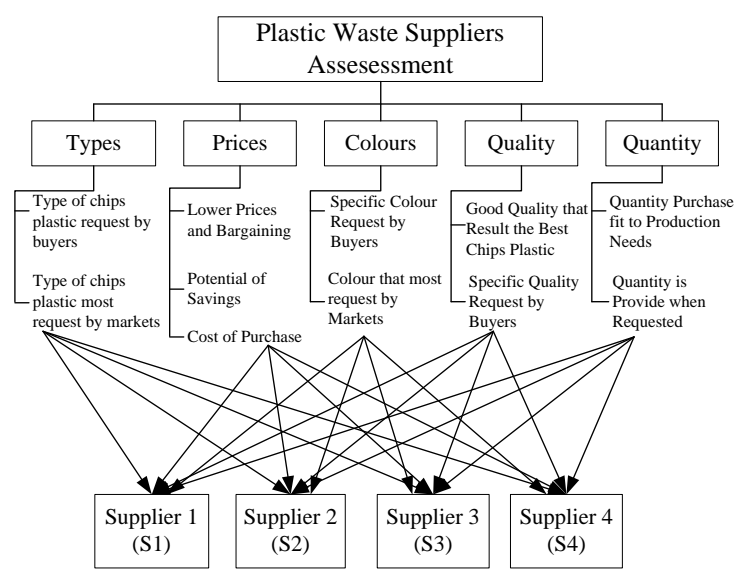

Fig. 6 Criteria and Sub-Criteria Assessment of Plastic Waste Suppliers With Approach Analysis Hierarchy Process (AHP) Structure (Modified from The 1st AICOSTS).

\subsection{Plastic Waste Suppliers Assessment}

At the AHP structure, assigning weights to each criterion, namely by way of comparison in pairs. Wherein if the assessment between the both criteria considered equally important as it is rated 1 for both criteria, whereas when there is a difference which one is more important, these criteria are given greater value than the others, namely $3,5,7$, or 9 , in accordance with level of importance of the other criteria into comparison.

Table 1. Pairwise comparisons Of Plastic Waste (Raw Materials) Supplier Selection.

(Modified from The 1st AICOSTS).

\begin{tabular}{llllll}
\hline & Types & Prices & Colours & Quality & Quantity \\
\hline Types & 1,00 & 1,00 & 3,00 & 1,00 & 3,00 \\
Prices & 1,00 & 1,00 & 2,00 & 1,00 & 2,00 \\
Colours & 1,00 & 0,50 & 1,00 & 0,50 & 2,00 \\
Quality & 0,50 & 0,33 & 1,00 & 1,00 & 2,00 \\
Quantity & 0,33 & 0,20 & 0,33 & 0,33 & 1,00 \\
Total & 3,83 & 3,03 & 7,33 & 3,83 & 10,00 \\
\hline
\end{tabular}

At this stage compares the criteria for the purchase of raw materials of plastic waste and assessment of the level of priority (comparative) or which become more important relative to one another criterion, namely the criteria of the type, price, color, quality, quantity and time of delivery of the raw material of plastic waste.

Table 2. Weight Calculation of Each Criterion (Modifications of the First AICOSTS).

\begin{tabular}{lllllll}
\hline & Types & Prices & Col & Qual & Q'ty & Weight \\
\hline Types & 0,26 & 0,33 & 0,41 & 0,26 & 0,30 & 0,31 \\
Prices & 0,26 & 0,33 & 0,27 & 0,26 & 1,00 & 0,42 \\
Col & 0,26 & 0,16 & 0,14 & 0,13 & 0,20 & 0,18 \\
Qual & 0,13 & 0,11 & 0,14 & 0,26 & 0,20 & 0,17 \\
Q'ty & 0,09 & 0,07 & 0,05 & 0,09 & 0,10 & 0,08 \\
\hline
\end{tabular}


From the table above, obtained weighting of each criterion are sequenced: $0.27 ; 0.23$; $0.15 ; 0.18 ; 0.07$ and 0.10 .

\subsection{Plastic Waste Suppliers Assessment}

Assessment of suppliers made by the buyer has consideration of types of plastic waste, price, color, quality, quantity and delivery time. After the manufacturer considers these criteria, the manufacturer will consider buying plastic waste.

The next stage is to weigh up the weight value of each supplier. The value is obtained by summing the results of multiplication of the burden of each sub-criterion is concerned.

Table 3. Final Suppliers Assessment (Modifications of the First AICOSTS).

\begin{tabular}{lccccc}
\hline $\begin{array}{l}\text { Citeria/Sub- } \\
\text { Criteria }\end{array}$ & Weight & $\begin{array}{c}\text { Supplier } \\
1\end{array}$ & $\begin{array}{c}\text { Supplier } \\
2\end{array}$ & $\begin{array}{c}\text { Supplier } \\
3\end{array}$ & $\begin{array}{c}\text { Supplier } \\
4\end{array}$ \\
\hline Types & $\mathbf{0 , 3 0}$ & & & & \\
(T1) & 0,20 & 0,345 & 0,125 & 0,255 & 0,275 \\
(T2) & 0,11 & 0,277 & 0,156 & 0,334 & 0,233 \\
Prices & $\mathbf{0 , 2 6}$ & & & & \\
(P1) & 0,12 & 0,637 & 0,124 & 0,135 & 0,104 \\
(P2) & 0,09 & 0,267 & 0,276 & 0,176 & 0,281 \\
(P3) & 0,05 & 0,231 & 0,311 & 0,323 & 0,135 \\
Colours & $\mathbf{0 , 1 7}$ & & & & \\
(C1) & 0,09 & 0,313 & 0,215 & 0,357 & 0,115 \\
(C2) & 0,08 & 0,274 & 0,197 & 0,276 & 0,253 \\
Quality & $\mathbf{0 , 1 9}$ & & & & \\
(Q1) & 0,08 & 0,471 & 0,211 & 0,216 & 0,102 \\
(Q2) & 0,11 & 0,383 & 0,276 & 0,139 & 0,202 \\
Quantity & $\mathbf{0 , 0 8}$ & & & & \\
(Qt1) & 0,03 & 0,376 & 0,219 & 0,212 & 0,193 \\
(Qt2) & 0,05 & 0,289 & 0,319 & 0,201 & 0,191 \\
$\begin{array}{l}\text { The Final } \\
\text { Weight }\end{array}$ & & & & & \\
Value & & $\mathbf{0 , 3 6 2}$ & $\mathbf{0 , 2 0 2}$ & $\mathbf{0 , 2 3 7}$ & $\mathbf{0 , 1 9 9}$ \\
\hline
\end{tabular}

As shows in the table supplier assessment above, the supplier 1 has the highest value of 0.359 , followed by the supplier 3 with a value of 0.235 , supplier 2 with a value of 0.205 and suppliers 4 with a value of 0,201 .

\section{Conclusions}

Based on analysis by using scorecards and gap analysis models it can be concluded as follows:

1. Based on the results of calculations by AHP and model of supplier evaluation form to rank several suppliers based on several criteria. The order of suppliers based we provide $1,3,2$ and 4, in which the highest value is first supplier with the value 0.362 , followed by the supplier 3 with a value of 0.237 , supplier 2 with a value of 0202 and suppliers 4 with a value of 0.199 . The sequence is a reflection of the most satisfying and fulfilling production needs.

2. Most of the current problems are getting raw materials that fluctuate and price compete between one supplier to another supplier. In addition, plastic waste raw materials are sometimes difficult to obtain because it competes with other potential buyers, especially 
from other areas such as Medan. These conditions will create a very tight competition and potentially disrupt the stability of raw material supply in the region of Aceh. This is definitely very disturbing the SC, especially for processing plastic waste into plastic chips in serround of Aceh today.

3. To meet the requirements of raw materials for manufacturing, manufacturing (processing industrial waste into plastic chips), cooperation with many suppliers to get some sort of plastic waste that is needed by the producers where demand is a reflection of the buyer. Demand in the plastic industry is transformed into a final plastic product, undertaken to keep the production (capacity) needs of both short and lengthy period.

4. Loyalty of suppliers sometimes is a problem because in this matter the effect of market mechanisms, where the highest bidder (the best) will obtain raw materials more quickly.

\section{REFERENCES}

[1] H. Balfaqih, M. T. Al-Nory, Z. M. Nopiah, and N. Saibani, "Environmental and economic performance assessment of desalination supply chain," Desalination, vol. 406, pp. 2-9, 2017.

[2] M. K. Lim, M.-L. Tseng, K. H. Tan, and T. D. Bui, "Knowledge management in sustainable supply chain management: Improving performance through an interpretive structural modelling approach," J. Clean. Prod., vol. 162, pp. 806-816, 2017.

[3] T. L. Saaty, "Relative measurement and its generalization in decision making why pairwise comparisons are central in mathematics for the measurement of intangible factors the analytic hierarchy/network process," RACSAM-Revista la Real Acad. Ciencias Exactas, Fis. y Nat. Ser. A. Mat., vol. 102, no. 2, pp. 251-318, 2008.

[4] J. Korpela, K. Kyläheiko, A. Lehmusvaara, and M. Tuominen, "An analytic approach to production capacity allocation and supply chain design," Int. J. Prod. Econ., vol. 78, no. 2, pp. 187-195, 2002.

[5] E. Aghezzaf, "Capacity planning and warehouse location in supply chains with uncertain demands," J. Oper. Res. Soc., vol. 56, no. 4, pp. 453-462, 2005.

[6] J. Y. Jung, G. Blau, J. F. Pekny, G. V Reklaitis, and D. Eversdyk, "A simulation based optimization approach to supply chain management under demand uncertainty," Comput. Chem. Eng., vol. 28, no. 10, pp. 2087-2106, 2004.

[7] R. S. Russell and B. W. Taylor, "Operation management: Quality and competitiveness in a global environment," Hoboken John Wiley Sons, 2006.

[8] L. Li, Supply chain management: Concepts, techniques and practices: Enhancing value through collaboration. World scientific publishing company, 2007.

[9] S. Chopra and P. Meindl, "Supply chain management. Strategy, planning \& operation," in Das summa summarum des management, Springer, 2007, pp. 265-275.

[10] R. M. Morgan and S. D. Hunt, "The commitment-trust theory of relationship marketing," $J$. Mark., vol. 58, no. 3, pp. 20-38, 1994.

[11] T. L. Saaty, "Axiomatic foundation of the analytic hierarchy process," Manage. Sci., vol. 32, no. 7, pp. 841-855, 1986.

[12] B. G. Merkin, Group Choice. NY: John Wiley \& Sons, 1979.

[13] F.-H. F. Liu and H. L. Hai, "The voting analytic hierarchy process method for selecting supplier,” Int. J. Prod. Econ., vol. 97, no. 3, pp. 308-317, 2005.

[14] R. M. Yusuff, K. P. Yee, and M. S. J. Hashmi, "A preliminary study on the potential use of the analytical hierarchical process (AHP) to predict advanced manufacturing technology (AMT) implementation," Robot. Comput. Integr. Manuf., vol. 17, no. 5, pp. 421-427, 2001.

[15] M. C. Y. Tam and V. M. R. Tummala, "An application of the AHP in vendor selection of a telecommunications system," Omega, vol. 29, no. 2, pp. 171-182, 2001.

[16] X. Yu and S. Jing, "A decision model for supplier selection considering trust," Chinese Bus. 
Rev., vol. 3, no. 6, pp. 15-20, 2004.

[17] O. S. Vaidya and S. Kumar, “Analytic hierarchy process: An overview of applications," Eur. J. Oper. Res., vol. 169, no. 1, pp. 1-29, 2006.

[18] S. Yahya and B. Kingsman, "Vendor rating for an entrepreneur development programme: a case study using the analytic hierarchy process method," J. Oper. Res. Soc., vol. 50, no. 9, pp. 916930, 1999.

[19] L. G. Vargas, "An overview of the analytic hierarchy process and its applications," Eur. J. Oper. Res., vol. 48, no. 1, pp. 2-8, 1990.

[20] Y. Wind and T. L. Saaty, "Marketing applications of the analytic hierarchy process," Manage. Sci., vol. 26, no. 7, pp. 641-658, 1980.

[21] E. H. Forman, "Decision support for executive decision makers," Inf. Strateg. Exec. J., vol. 1, no. 4, pp. 4-14, 1985.

[22] D. F. Ross, Competing through supply chain management: creating market-winning strategies through supply chain partnerships. Springer Science \& Business Media, 1997.

[23] R. C. Steven and J. C. Roger, "Logistics strategy: does it travel well?," Logist. Inf. Manag., vol. 10, no. 5, pp. 224-234, 1997.

[24] S. E. Fawcett, L. L. Stanley, and S. R. Smith, "Developing a logistics capability to improve the performance of international operations," J. Bus. Logist., vol. 18, no. 2, p. 101, 1997.

[25] J. Olhager and E. Selldin, "Supply chain management survey of Swedish manufacturing firms," Int. J. Prod. Econ., vol. 89, no. 3, pp. 353-361, 2004.

[26] J. Motwani, L. Larson, and S. Ahuja, "Managing a global supply chain partnership," Logist. Inf. Manag., vol. 11, no. 6, pp. 349-354, 1998.

[27] C. C. Li, Y. P. Fun, and J. S. Hung, "A new measure for supplier performance evaluation," IIE Trans., vol. 29, no. 9, pp. 753-758, 1997.

[28] T. Y. Choi and J. L. Hartley, "An exploration of supplier selection practices across the supply chain,” J. Oper. Manag., vol. 14, no. 4, pp. 333-343, 1996.

[29] J. Schmitz and K. W. Platts, "Supplier logistics performance measurement: Indications from a study in the automotive industry," Int. J. Prod. Econ., vol. 89, no. 2, pp. 231-243, 2004. 